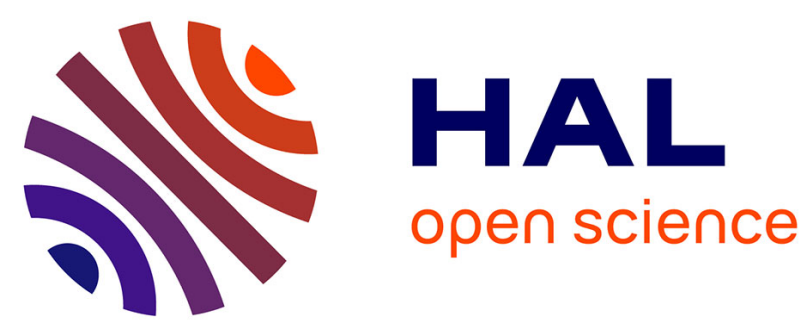

\title{
Improved EIS Analysis of the Electrochemical Behaviour of Carbon Steel in Alkaline Solution
}

\author{
Sara Chakri, Isabelle Frateur, Mark E Orazem, Eliane Sutter, Mai Tran Tron
} Long, Bernard Tribollet, Vincent Vivier

\section{- To cite this version:}

Sara Chakri, Isabelle Frateur, Mark E Orazem, Eliane Sutter, Mai Tran Tron Long, et al.. Improved EIS Analysis of the Electrochemical Behaviour of Carbon Steel in Alkaline Solution. Electrochimica Acta, 2017, 246, pp.924 - 930. 10.1016/j.electacta.2017.06.096 . hal-01555457

\section{HAL Id: hal-01555457 \\ https://hal.sorbonne-universite.fr/hal-01555457}

Submitted on 4 Jul 2017

HAL is a multi-disciplinary open access archive for the deposit and dissemination of scientific research documents, whether they are published or not. The documents may come from teaching and research institutions in France or abroad, or from public or private research centers.
L'archive ouverte pluridisciplinaire HAL, est destinée au dépôt et à la diffusion de documents scientifiques de niveau recherche, publiés ou non, émanant des établissements d'enseignement et de recherche français ou étrangers, des laboratoires publics ou privés. 


\title{
Improved EIS Analysis of the Electrochemical Behaviour of Carbon Steel in Alkaline Solution
}

S. Chakri, ${ }^{1}$ I. Frateur, ${ }^{1}$ M.E. Orazem, ${ }^{2}$ E.M.M. Sutter, ${ }^{1}$ T.T.M. Tran,,${ }^{1 *}$ B. Tribollet, ${ }^{1}$ V. Vivier ${ }^{1}$ 1- Sorbonne Universités, UPMC Univ Paris 06, CNRS, Laboratoire Interfaces et Systèmes Electrochimiques, 4 place Jussieu, F-75005, Paris, France

2 - Department of Chemical Engineering, University of Florida, Gainesville, Florida 32611, USA

* Corresponding author

E-mail address: mai.tran_trong_long@upmc.fr

\begin{abstract}
Steady-state polarization curves, X-ray photoelectron spectroscopy, and impedance spectroscopy were used to explore the electrochemical properties for carbon steel in alkaline electrolytes. The complex-capacitance representation allowed determination of a capacitance value at high frequency, from which the oxide film thickness could be estimated. These results are in good agreement with values obtained using the power-law model, providing a single mathematical model that is shown to apply in both the anodic and cathodic domains for the characterization of an oxide layer.
\end{abstract}

Keywords: Carbon steel; Complex-capacitance plot; Power-law model; Oxide film; Electrochemical impedance spectroscopy 


\section{Introduction}

Carbon steel is widely used as a reinforcement for concrete. Within the high alkaline environment of concrete $(\mathrm{pH}>12.5)$, the steel surface is covered by a dense, adherent, and passive oxide layer of thickness on the order of several $\mathrm{nm}[1]$, giving rise to a natural protection against corrosion. Both carbonation and penetration of chlorides induce the local breakdown of this oxide film and the initiation of pitting corrosion. To analyze the overall corrosion mechanism, it is thus necessary to characterize the oxide layer and to determine the rates of the anodic and cathodic reactions that take place at a passivated surface mainly composed of iron oxides. While the behaviour of the passive film on iron in the anodic range [2-6] is well documented, the electrochemical reduction of oxygen on iron and steel has been poorly investigated, and only few authors have characterized in detail the cathodic reactions on passive iron oxide layer in alkaline solutions [7-10].

The oxygen-reduction reaction (ORR) usually takes place at porous oxidized surfaces (surface oxides and rust layers) that are complex both in composition and morphology [11]. This reaction depends strongly on the state of the electrode surface and can be influenced by many factors such as temperature or impurities, confounding the understanding of this mechanism.

Different authors have shown that in alkaline solutions the ORR at the passive oxide layer takes place at electrode potentials where partial reduction of oxide layers can also occur. Taking into account the solubility of oxygen in aqueous electrolytes (about $210^{-4} \mathrm{~mol} / \mathrm{L}$ at room temperature), oxygen reduction is the major cathodic reaction, as compared to the hydrogen evolution reaction (HER) for $\mathrm{pH}$ values $>12$ [12]. Oxygen recycling results from a high peroxide decomposition turnover, and, as a consequence, the apparent number of electrons exchanged per oxygen molecule is strongly dependent on mass transport. This result may be particularly important for porous surfaces like rust layers associated with atmospheric corrosion and corrosion of reinforcement in concrete. Indeed, Vago et al. [13] showed that the ORR has 
to be seen as a 2-electron mechanism (thus a partial reduction of oxygen) when the oxidized surface consisted of iron hydroxides $(\mathrm{FeOOH})$; whereas, for an oxidized surface composed of magnetite, the 4-electron mechanism is predominant. Moreover, Stratmann et al. [12] concluded that oxygen is reduced into the oxide layer and not at the metal surface. In addition, the ORR on steel is complex since it depends on the state of the oxide film including the $\mathrm{Fe}^{2+} / \mathrm{Fe}^{3+}$ ratio. The ORR has been shown to be mediated by $\mathrm{Fe}(\mathrm{II})$ sites formed by reduction of the passive layer [14].

The objective of this work is to show that electrochemical impedance spectroscopy (EIS) can provide further insights into the mechanism of cathodic reaction at an oxide layer. Such a study is of interest since the cathodic behaviour of steel may govern the kinetics of rebar degradation. In previous works, EIS has been shown to be a powerful method for separating different electrochemical contributions to the overall reaction and also to provide quantitative estimation of the properties of an oxide layer using numerical simulation [15-18]. This method is used in the present case for the anodic range in the passive domain and for different cathodic potentials at which ORR is assumed to be the main cathodic reaction. This is a new approach combining the power-law model and the complex capacitance representation that allows in-situ characterization of oxide films. This development is important because ex-situ analyses are confounded by changes in the oxide film after polarization is removed. A single model is used here to apply for the entire potential range, in both the anodic and the cathodic domains.

\section{Experimental}

The C15 mild steel used for the reinforcement of building concrete was selected as sample material for this work. Its nominal composition was in agreement with EN 10277-2 standards. The electrochemical cell used was a classic three-electrode cell. The working electrode (WE) consisted of a C15 mild steel rotating disk electrode (RDE) with an exposure area of about 0.5 
$\mathrm{cm}^{2}$, corresponding to the cross section of an $8 \mathrm{~mm}$ diameter steel rebar. In order to protect the lateral wall of the WE, the rebar was covered with an insulating cataphoretic paint before being embedded in an epoxy resin. Before each electrochemical measurement, the WE was mechanically polished with SiC papers down to grade 1200, then degreased in an ultrasonic bath for 1 minute, first in ethanol then in distilled water, and finally dried under an inert gas flow. A platinum grid with a large surface area was used as a counter electrode, and a saturated $\left(\mathrm{K}_{2} \mathrm{SO}_{4}\right)$ mercury sulphate electrode $\left(\mathrm{MSE}-\mathrm{E}^{0}=0.64 \mathrm{~V} / \mathrm{SHE}\right)$ was used as a reference electrode. The electrochemical cell was filled with a $0.1 \mathrm{M} \mathrm{NaOH}$ air saturated solution at $\mathrm{pH}$ $=13$. Electrochemical measurements were performed at room temperature with a Reference 600 potentiostat/galvanostat from GAMRY Instruments. The behaviour of steel in $0.1 \mathrm{M} \mathrm{NaOH}$ solution was studied by steady-state electrochemical measurements (polarization curves and EIS).

\section{Mathematical Development}

When the electrochemical impedance of an oxide film can be described by a constant-phase element (CPE), at least in the high frequency range, it has been shown that the power-law model (PLM) [15-19] is a good candidate for describing the thin film properties. This model is based on a variation of the resistivity along the direction normal to the electrode according to a modified power law, i.e.,

$$
\rho(x)=\rho_{\delta}\left(\frac{\rho_{\delta}}{\rho_{0}}+\left(1-\frac{\rho_{\delta}}{\rho_{0}}\right)\left(\frac{x}{\delta}\right)^{\gamma}\right)^{-1}
$$

where $\rho_{0}$ is the resistivity at the metal/oxide interface and $\rho_{\delta}$ is the resistivity at the oxide/electrolyte interface. This description also accounts for bounded values of the resistivity at both the metal/oxide and oxide/solution interfaces. 
Under assumption of a uniform permittivity along the film thickness, the expression of the impedance can be obtained by integration along the film thickness from the position $\mathrm{x}=0$, corresponding to the coordinate at the metal/oxide interface, to the $\mathrm{x}=\delta$, corresponding to the coordinate at the oxide/solution interface. According to Hirschhorn et al. [15], for a frequency lower than $f_{\delta}=\left(2 \pi \rho_{\delta} \varepsilon \varepsilon_{0}\right)^{-1}$, an analytic expression of the impedance of the film can be written as

$$
Z_{F}=g(\alpha) \frac{\delta \rho_{\delta}{ }^{1-\alpha}}{\left(\rho_{0}^{-1}+j \omega \varepsilon \varepsilon_{0}\right)^{\alpha}}
$$

where $\alpha=\frac{\gamma-1}{\gamma}$ and $g(\alpha)=1+2.88(1-\alpha)^{2.375}$.

This impedance shows a CPE behaviour in the high-frequency range $\left(f<f_{\delta}\right)$ with $\alpha$ and $Q$ as parameters and

$$
Q=\frac{\left(\varepsilon \varepsilon_{0}\right)^{\alpha}}{g \delta \rho_{\delta}^{1-\alpha}}
$$

Equation (3) shows that only the product $\delta \rho_{\delta}^{1-\alpha}$ can be determined from the characterization of the oxide film with known dielectric constant in a limited frequency domain. Consequently, additional methods are required to measure independently the thickness $\delta$ of the oxide layer. Surface analyses have often been used by the past [18-21], but recently it has been shown that the extrapolation of the complex-capacitance diagram at infinite frequency can be a reliable way to determine the thickness of the layer $[22,23]$. The complex capacitance is calculated using the impedance data corrected for the electrolyte resistance, i.e.,

$$
C(\omega)=\frac{1}{j \omega\left(Z(\omega)-R_{e}\right)}
$$

Because the power-law model was shown to be equivalent, from an electrical point of view, to a set of Voigt elements in series, two limiting cases can be predicted. In the low-frequency 
domain, the current tends towards the dc value and a pure resistive behaviour is expected. Conversely, for very high frequency, all resistances are negligible with respect to the impedance corresponding to the capacitance, and the overall impedance is a pure capacitance equal to the sum of all capacitances of the Voigt elements in series. The physical meaning of this capacitance is linked with the dielectric properties of the electrochemical interface, and it thus provides an estimate of the oxide film capacitance in the high frequency domain. From this value, and using the usual formula for a parallel plate capacitor $C_{o x}=\frac{\varepsilon \varepsilon_{0}}{\delta}$, an estimate of the thickness of the layer could be obtained. In a last step, this thickness can be used in Equation (3) and from the values of the CPE parameters, $Q$ and $\alpha$, the resistivity at the oxide-electrolyte interface $\rho_{\delta}$ can be deduced [23].

\section{Results and Discussion}

The experimental results include polarization curves and impedance diagrams.

\subsection{Current-Potential Curves}

The current-potential curves in anodic and cathodic domains were evaluated separately.

\subsubsection{Anodic Domain}

Preliminary measurements showed that a steady-state behaviour was reached only after 60 hours of immersion, resulting from slow evolution in composition, structure and thickness of the passive film when the sample is immersed into a $0.1 \mathrm{M} \mathrm{NaOH}$ solution. The protocol for measuring polarization curves on a point by point basis was to hold the system at open-circuit for 60 hours and then to apply set potentials, recording the steady-state current that could be measured after an elapsed time of 18 hours. Two different curves are plotted in Figure 1, showing the good reproducibility of the measurements. The second set of experiments was performed in a more limited potential range than for the first set to avoid the transpassive region. 
From the steady-state polarization curves, the passive and corrosion current densities were estimated to be c.a. $50 \mathrm{nA} / \mathrm{cm}^{2}$.

\subsubsection{Cathodic Domain}

Since the ORR is strongly dependent on mass transport, the cathodic polarization curves were obtained using a rotating disk electrode (RDE) in order to control hydrodynamic conditions and, thus, the thickness of the diffusion layer (Figure 2).

The steady-state cathodic polarization curve was obtained at a rotation rate $\Omega=150 \mathrm{rpm}$ by performing measurements from $-1.70 \mathrm{~V} / \mathrm{MSE}$ to a potential close to $E_{\text {corr }}$ by successive $50 \mathrm{mV}$ steps, using the same protocol as was used for the anodic curves to reach the steady-state condition. The increase of the cathodic current with increasing cathodic potential was followed by a diffusion-limited plateau, between -1.2 and $-1.5 \mathrm{~V} / \mathrm{MSE}$, mainly attributed to the ORR.

For larger cathodic overpotentials ( $E<-1.5 \mathrm{~V} / \mathrm{MSE})$, the observed increase of the current was attributed to the water reduction reaction. Following reference [14], since the reduction of the oxide film contributes to the overall cathodic current in the potential domains where the ORR takes place, EIS was used to characterize the oxide layer as a function of the applied potential.

\subsection{Electrochemical Impedance Spectroscopy}

Impedance measurements were performed at the corrosion potential and in both anodic and cathodic domains. Interpretation of the impedance measurements at the corrosion potential was augmented by use of X-ray photoelectron spectroscopy (XPS) analysis to extract film thickness.

\subsubsection{Anodic Domain}

EIS analyses were first performed in the passive domain, in which the cathodic faradaic reaction is not expected to contribute to the impedance response and the system can be described as a dielectric oxide layer in series with the double layer capacitance. Because the double layer capacitance is usually much larger than that of a thin oxide film, it can be neglected in a first 
approximation. According to Figure 1, at an anodic potential between $E_{\text {corr }}$ and about 0.2 V/MSE, the anodic current corresponds to the passive current, and the impedance is the impedance of the oxide film given by Equation (2). For example, the impedance diagram obtained at $-0.6 \mathrm{~V} / \mathrm{MSE}$ is presented in Figure 3.

The corresponding oxide film thickness was obtained from XPS measurements to be $2.4 \mathrm{~nm}$, yielding, for an assumed dielectric constant equal to 12 , a capacitance of $4.5 \mu \mathrm{F} / \mathrm{cm}^{2}$ [25]. In the case of dielectric systems, the complex capacitance representation (Cole-Cole format) has been shown to be well suited for the determination of the capacitance of the film, after correcting the data for the electrolyte resistance [24]. An example is given in Figure 4 for a potential of $-0.6 \mathrm{~V} / \mathrm{MSE}$.

The thickness value obtained by use of XPS provides a capacitance value reported on Figure 4 under the assumption that $\varepsilon=12$. This value corresponds well to an extrapolation of the complex capacitance to the real axis; thus, the complex capacitance plots were used to extract values of capacitance for potentials away from the corrosion potential.

The capacitance and thickness values resulting from this analysis are presented in Table 1. Application of the power-law model allowed identification of $\rho_{\delta}$ as a function of applied potential. The uncertainty of this value is large. A propagation of error analysis using assumed standard deviations for regressed parameters suggested that, with the exception of the value obtained at a potential $E=-1 \mathrm{~V} / \mathrm{MSE}$, the variation of $\rho_{\delta}$ is not statistically significant. The corresponding characteristic frequencies $f_{\delta}=1 /\left(2 \pi \varepsilon \varepsilon_{0} \rho_{\delta}\right)$ are larger than the experimentally measured frequencies.

The impedance under anodic potentials was assumed to be that of the oxide layer represented by the impedance of the power law model (Equation (2)). The experimental data corresponding 
to Figure 3 and associated regression results are presented in Figure 5 in Bode and electrolyteresistance-corrected Bode formats [16].

In ordinary Bode plots (Figures $5 \mathrm{a}$ and $5 \mathrm{~b}$ ) the regression seems very good in the entire frequency range, but, as mentioned in reference [16], the electrolyte resistance obscures the impedance behaviour in the high-frequency range. The electrolyte-resistance-corrected Bode plots (Figures 5c and 5d) show a disagreement between the regressed curve and the experimental data in the high frequency domain. As described in reference [16], the discrepancy between simulation and experimental data at high frequency can be attributed to the geometric effect of the electrode resulting from current and potential distributions at the electrode surface. The geometric effect has an effect on the impedance value for a frequency larger than $f_{c}=\frac{1}{8 R_{e} C_{o x}}$ in the case of a disk electrode embedded in an insulator [16]. The geometric effect was not taken into account in Equation (2), leading to a discrepancy between experimental and simulated values. For this reason, the impedance data were regressed in a narrow frequency domain $(f<200 \mathrm{~Hz})$, and, above this frequency, the data were simulated using parameters determined by the fitting. The results of the regression are given in Table 1 . The resistivity at the metal/oxide interface $\left(\rho_{0}\right)$ was in the range expected for an insulator. Since the thickness of the layer was obtained with an estimated accuracy of $10 \%$ and the exponent of $\rho_{\delta}$ in Equation (2) is small, the resistivity at the oxide/electrolyte interface was determined with a poor accuracy. Nevertheless, the variation of the resistivity inside the oxide layer can be plotted as shown in Figure 6. In the present model, the double-layer capacitance, which is at the interface between the oxide layer and the electrolyte and which should appear in series with the impedance of the oxide, was not taken into account. Assumption of a usual value of $50 \mu \mathrm{F} / \mathrm{cm}^{2}$ for the double layer capacitance yields an error estimate of 5 to $10 \%$ with respect to the value of the oxide capacitance reported in Table 1. 


\subsubsection{Cathodic Domain}

At high cathodic overpotentials, the oxide layer was assumed to be progressively reduced. However, no special feature could be seen on the current-potential curve (Figure 2) that could be attributed to the oxide layer evolution. Using the approach described previously for the analysis of the EIS diagrams obtained in the anodic range, an analysis based on the complexcapacitance plot was used to indicate whether the oxide layer is still present at the surface of the electrode.

The complex-capacitance plots (not shown) were found to be very similar to the plot obtained at the corrosion potential, shown in Figure 4, indicating the presence of an oxide layer over a wide cathodic potential range. From these data, the thickness of the oxide layer was estimated and is reported in Table 1 and in Figure 7. For a potential lower than -0.8 V/MSE, the oxide thickness decreased significantly with potential, and extrapolation suggests that the layer vanished completely for potentials more negative than -1.1 V/MSE.

As an example, the impedance measured at $E=-0.9 \mathrm{~V} / \mathrm{MSE}$ is given in Figure 8 . In this Nyquist diagram, the impedance appears as a single depressed semicircle. The polarization resistance has a value of $11 \mathrm{k} \Omega . \mathrm{cm}^{2}$ and corresponds to the faradaic impedance of the oxygen reduction in series with the electrolyte resistance and the electronic resistance of the oxide layer (see below). The impedance of the oxide layer at zero frequency is given by

$$
Z_{F}(0)=g(\alpha) \delta \rho_{\delta}^{1-\alpha} \rho_{0}^{\alpha}
$$

Its value was evaluated to be larger than $8.6 \times 10^{5}$ and thus played no role in the polarization resistance value.

\subsubsection{Model of the Interface}

At the corrosion potential, the overall impedance is composed of two independent branches (Figure 9), one corresponding to the anodic reaction and the other corresponding to the cathodic 
reaction [24]. The two branches are connected to the metal on one side and to the electrolyte resistance on the other side. The anodic branch corresponds to the circuit used to analyze the experimental data in the anodic potential range. The anodic branch is consistent with oxidation of the steel at the steel-oxide interface, contributing to a distribution of charged species, e.g., vacancies, within the oxide. The PLM accounts for the associated resistivity distribution. A second reaction takes place at the oxide-electrolyte interface. As the impedance of the reactions at the metal-oxide and oxide-electrolyte interfaces are expected to be small as compared to the dielectric impedance of the oxide, these terms are neglected in Figure 9. The faradaic impedance of oxygen reduction is very large and this impedance can be neglected because it has a very small contribution to the overall response of the system. The assumption that the faradaic impedance of the oxygen reduction could be neglected appeared to apply as well to the measurements obtained at the corrosion potential.

At potentials more cathodic than the corrosion potential, the electrons generated at the oxide/electrolyte interface are transferred to the metal through the oxide layer and an electronic resistance must be introduced. This resistance is different than the resistance used in the PLM model because the resistors in the PLM model are attributed to the ionic resistance corresponding to the presence of vacancies and in some cases to inserted ions. As a result, the transport of charges is performed by ionic carriers for the anodic branch and by electrons for the cathodic branch (Figure 9). The electronic resistance is added to the cathodic faradaic impedance, and, in general, only the sum of the charge-transfer resistance and the oxide layer resistance can be obtained from regression.

In the cathodic range, when the impedance of the cathodic branch is small with respect to $Z_{F}(0)$, the expression of the PLM model (Equation (2)) is reduced to its CPE part, i.e.,

$$
Z_{F}=g(\alpha) \frac{\delta \rho_{\delta}{ }^{1-\alpha}}{\left(j \omega \varepsilon \varepsilon_{0}\right)^{\alpha}}
$$


Thus, in the potential range (-0.8 V/MSE, $-1 \mathrm{~V} / \mathrm{MSE})$, the $\rho_{0}$ value could not be determined by regression (in Table $1 \rho_{0}$ is indicated as "undefined").

In the low cathodic potential range (positive to $-0.8 \mathrm{~V} / \mathrm{MSE}$ ), oxygen reduction is under pure kinetic control and the faradaic expression is reduced to a charge-transfer resistance $R_{t}$. For lower potential $(E<-0.8 \mathrm{~V} / \mathrm{MSE})$, mass transport plays a role and the faradaic expression corresponds to a charge-transfer resistance in series with a diffusion impedance. With the model corresponding to the equivalent circuit given in Figure 9 in which the faradaic impedance is replaced by a charge-transfer resistance, the sum of the charge-transfer resistance $R_{t}$ and the electronic resistance of the oxide layer $R_{o x}$ may be obtained by regression. These results are plotted in Figure 10 as a function of the electrode potential. In a semi-logarithmic plot, this sum varies linearly with the potential as expected for Tafel kinetics. The Tafel coefficient was about $175 \mathrm{mV} /$ decade, which is in agreement with values found in the literature. This behaviour shows that the electronic film resistance is likely to be negligible in comparison with $R_{t}$. Under the assumption that the electronic resistance is independent of potential, it can be concluded that this resistance is smaller than $1 \mathrm{k} \Omega \mathrm{cm}^{2}$.

\section{Conclusion}

A combination of experimental techniques, including steady-state polarization curves, X-ray photoelectron spectroscopy, and electrochemical impedance spectroscopy, were used to explore the electrochemical properties for carbon steel in alkaline electrolytes. At the corrosion potential, the capacitance derived from XPS analyses was shown to conform to the extrapolation to the high-frequency limit of a complex capacitance in a Cole-Cole representation. Such extrapolation was used at other applied potentials to obtain the oxide film thickness. Application of the power-law model allowed identification of $\rho_{\delta}$ as a function of applied potential. 
Under anodic potentials, the impedance response corresponded to that of the oxide. Under cathodic potentials, the impedance response included the parallel contribution of the oxygen reduction reaction, treated here as a charge-transfer resistance. The exponential dependence of the regressed value, which nominally included the series contribution of the electronic resistance of the oxide, suggested that the contribution of the electronic resistance of the oxide was small and could be neglected. 


\section{References}

[1] Y.M. Tang, Y.F. Miao, Y. Zuo, G.D. Zhang, C.L. Wang, Corrosion behavior of steel in simulated concrete pore solutions treated with calcium silicate hydrates, Constr. Build. Mater. 30 (2012) 252.

[2] P. Ghods, O.B. Isgor, G. McRae, T. Miller, The effect of concrete pore solution composition on the quality of passive oxide films on black steel reinforcement, Cem. Concr. Compos. 31 (2009) 2 .

[3] F.H. Karman, I. Felhosi, E. Kalman, I.Cserny, L. Kover, The role of oxide layer formation during corrosion inhibition of mild steel in neutral aqueous media, Electrochim. Acta 43 (1998) 69.

[4] L. Freire, X.R. Novoa, M.F. Montemor, M.J. Carmezim, Study of passive films formed on mild steel in alkaline media by the application of anodic potentials, Mater. Chem. Phys. 114 (2009) 962

[5] Y.S. Zhang, X.M. Zhu, M. Liu, R.X. Che, Effects of anodic passivation on the constitution, stability and resistance to corrosion of passive film formed on an Fe-24Mn-4Al-5Cr alloy, Appl. Surf. Sci. 222 (2004) 89.

[6] P. Lorbeer, W.J. Lorenz, The kinetics of iron dissolution and passivation in solutions containing oxygen, Electrochim. Acta 25 (1980) 375.

[7] N. Le Bozec, C. Compere, M. L'Her, A. Laouenan, D. Costa, P. Marcus, Influence of stainless steel surface treatment on the oxygen reduction reaction in seawater, Corros. Sci. 43 (2001) 765 . 
[8] S.L. Gojkovic, S.K. Zecevic, D.M. Drazic, Oxygen reduction on iron .Part VII. Temperature dependence of oxygen reduction on passivated iron in alkaline solutions, J. Electroanal. Chem. $399(1995) 127$.

[9] S. Zecevic, D.M. Drazic, S. Gojkovic, Oxygen reduction on iron. Part III. An analysis of the rotating disk-ring electrode measurements in near neutral solutions, J. Electroanal. Chem. 265 (1989) 179.

[10] S.L. Gojkovic, S.K. Zecevic, M.D. Obradovic, D.M. Drazic, Oxygen reduction on a duplex stainless steel, Corros. Sci. 40 (1998) 849.

[11] E.R. Vago, E.J. Calvo, M. Stratmann, Electrocatalysis of oxygen reduction at well-defined iron-oxide electrodes, Electrochim. Acta 39 (1994) 1655.

[12] M. Stratmann, J. Muller, The mechanism of the oxygen reduction on rust-covered metal substrates, Corros. Sci. 36 (1994) 327.

[13] E.R. Vago, E.J. Calvo, Oxygen electro-reduction on iron oxide electrodes: III. Heterogeneous catalytic $\mathrm{H}_{2} \mathrm{O}_{2}$ decomposition, J. Electroanal. Chem. 388 (1995) 161.

[14] E.J. Calvo, D.J. Schiffrin, The electrochemical reduction of oxygen on passive iron in alkaline-solutions, J. Electroanal. Chem. 243 (1988) 171.

[15] B. Hirschorn, M.E. Orazem, B. Tribollet, V. Vivier, I. Frateur, M. Musiani, ConstantPhase-Element Behavior Caused by Resistivity Distributions in Films I. Theory, J. Electrochem. Soc. 157 (2010) C452.

[16] B. Hirschorn, M.E. Orazem, B. Tribollet, V. Vivier, I. Frateur, M. Musiani, ConstantPhase-Element Behavior Caused by Resistivity Distributions in Films II. Applications, J. Electrochem. Soc. 157 (2010) C458. 
[17] M.E. Orazem, B. Tribollet, V. Vivier, D.P. Riemer, E. White, A. Bunge, On the Use of the Power-Law Model for Interpreting Constant-Phase-Element Parameters, J. Braz. Chem. Soc. 25 (2014) 532.

[18] M. Musiani, M.E. Orazem, N. Pebere, B. Tribollet, V. Vivier, Determination of resistivity profiles in anti-corrosion coatings from constant-phase-element parameters, Prog. Org. Coat. 77 (2014) 2076.

[19] R.H. Nilson, M.T. Brumbach, B.C. Bunker, Modeling the Electrochemical Impedance Spectra of Electroactive Pseudocapacitor Materials, J. Electrochem. Soc. 158 (2011) A678.

[20] M. BenSalah, R. Sabot, E. Triki, L. Dhouibi, P. Refait, M. Jeannin, Passivity of Sanicro28 (UNS N-08028) stainless steel in polluted phosphoric acid at different temperatures studied by electrochemical impedance spectroscopy and Mott-Schottky analysis, Corros. Sci. 86 (2014) 61.

[21] L. Hamadou, L. Ainouche, A. Kadri, S.A.A. Yahia, N. Benbrahim, Electrochemical impedance spectroscopy study of thermally grown oxides exhibiting constant phase element behaviour, Electrochim. Acta 113 (2013) 99.

[22] A.K. Jonscher, Admittance spectrocopy of systems showing low-frequency dispersion, Electrochim. Acta 35 (1990) 1595.

[23] M. Benoit, C. Bataillon, B. Gwinner, F. Miserque, M.E. Orazem, C. Sanchez-Sanchez, B. Tribollet, V. Vivier, Comparison of different methods for measuring the passive film thickness on metals, Electrochim. Acta 201 (2016) 340.

[24] M.E. Orazem, B. Tribollet, Electrochemical Impedance Spectroscopy, John Wiley \& Sons, Hoboken, 2008.

[25] S. Chakri, Thesis 2015, University Pierre et Marie Curie, Paris (France). 
Table 1: Capacitance values determined from the complex-capacitance plots, the corresponding layer thickness and the resistivity at the interface oxide/electrolyte and at the interface metal/oxide

\begin{tabular}{|c|c|c|c|c|c|c|c|}
\hline $\mathrm{V} / \mathrm{MSE}$ & $\begin{array}{c}C_{\mathrm{ox}} \\
\left(\mu \mathrm{F} / \mathrm{cm}^{2}\right)\end{array}$ & $\begin{array}{c}\delta \\
(\mathrm{nm})\end{array}$ & $\alpha$ & $\begin{array}{c}Q \\
\left(\mu \mathrm{F} / \mathrm{cm}^{2} \mathrm{~s}^{1-\alpha}\right)\end{array}$ & $\begin{array}{c}\rho_{\delta} \\
(\Omega \mathrm{cm})\end{array}$ & $\begin{array}{c}f_{\delta} \\
(\mathrm{MHz})\end{array}$ & $\begin{array}{c}\rho_{0} \\
(\Omega \mathrm{cm})\end{array}$ \\
\hline-0.3 & 4.2 & 2.5 & 0.89 & 38.9 & 1480 & 100 & $4.410^{14}$ \\
\hline-0.4 & 4.5 & 2.4 & 0.90 & 38.0 & 380 & 390 & $9.110^{13}$ \\
\hline-0.5 & 4 & 2.5 & 0.90 & 38.8 & 210 & 710 & $7.710^{13}$ \\
\hline-0.6 & 5 & 2.1 & 0.87 & 69.6 & 1380 & 110 & $4.410^{14}$ \\
\hline-0.7 & 5 & 2.1 & 0.86 & 86.5 & 1210 & 120 & $4.410^{14}$ \\
\hline-0.8 & 5 & 2.1 & 0.84 & 115 & 2390 & 63 & undefined \\
\hline-0.9 & 6 & 1.8 & 0.82 & 171 & 5400 & 28 & undefined \\
\hline-1.0 & 8 & 1.3 & 0.77 & 432 & 20900 & 7 & undefined \\
\hline
\end{tabular}




\section{Figure captions}

Figure 1

Anodic steady-state polarization curves of C15 mild steel measured after $60 \mathrm{~h}$ of immersion in $0.1 \mathrm{M} \mathrm{NaOH}$ solution at $E_{\text {corr }}$. The black curve was extended to the transpassive range; whereas, the red curve was stopped in the passive range.

Figure 2

Steady-state cathodic polarization curve of $\mathrm{C} 15$ mild steel in $0.1 \mathrm{M} \mathrm{NaOH}$ solution obtained after an initial immersion of $60 \mathrm{~h}$ at $E_{\text {corr }}$ with $\Omega=150 \mathrm{rpm}$. Measurements were performed between $-1.7 \mathrm{~V} / \mathrm{MSE}$ and $E_{\text {corr }}$ by successive $50 \mathrm{mV}$ steps.

Figure 3

Impedance diagram of $\mathrm{C} 15$ mild steel at $E=-0.6 \mathrm{~V} / \mathrm{MSE}$ after $60 \mathrm{~h}$ of immersion in $0.1 \mathrm{M}$ $\mathrm{NaOH}$ solution at $E_{\text {corr }}$.

Figure 4

Complex-capacitance diagram obtained for $\mathrm{C} 15$ mild steel at $-0.6 \mathrm{~V} / \mathrm{MSE}$. The red circle corresponds to the capacitance calculated with the thickness obtained from XPS analysis and compares well with the extrapolation performed on the complex capacitance plot (see text for details).

Figure 5

Experimental and simulated Bode plots corresponding to the results of Figure $3(E=-0.6$ V/MSE): (a) and (b) $\log (|\mathrm{Z}|)$ and phase as functions of $\log (\mathrm{f})$ without correction for ohmic 
resistance; (c) and (d) ) $\log (\mid \mathrm{Zl})$ and phase as functions of log (f) in electrolyte-resistancecorrected Bode representation $\left(\mathrm{R}_{\mathrm{e}}=21.2 \Omega \mathrm{cm}^{2}\right)$.

Figure 6

Simulation of the distribution of resistivity in the oxide layer at $-0.6 \mathrm{~V} / \mathrm{MSE}$ according to the power-law model applied to the experimental results of Figure 3.

Figure 7

Variation of the thickness of oxide layer on $\mathrm{C} 15$ mild steel in $0.1 \mathrm{M} \mathrm{NaOH}$ solution as a function of potential.

Figure 8

Nyquist diagram for $\mathrm{C} 15$ mild steel in $0.1 \mathrm{M} \mathrm{NaOH}$ solution at $E=-0.9 \mathrm{~V} / \mathrm{MSE}$.

Figure 9

Equivalent electrical circuit used for the $\mathrm{C} 15$ mild steel in $0.1 \mathrm{M} \mathrm{NaOH}$ solution in the cathodic potential range.

Figure 10

Regressed values of the sum $\left(R=R_{t}+R_{o x}\right)$ versus the potential in semi-logarithmic coordinates, according to the equivalent circuit of Figure 9, in which $Z_{F, O 2}$ is replaced by $R_{t}$. 
Figure 1

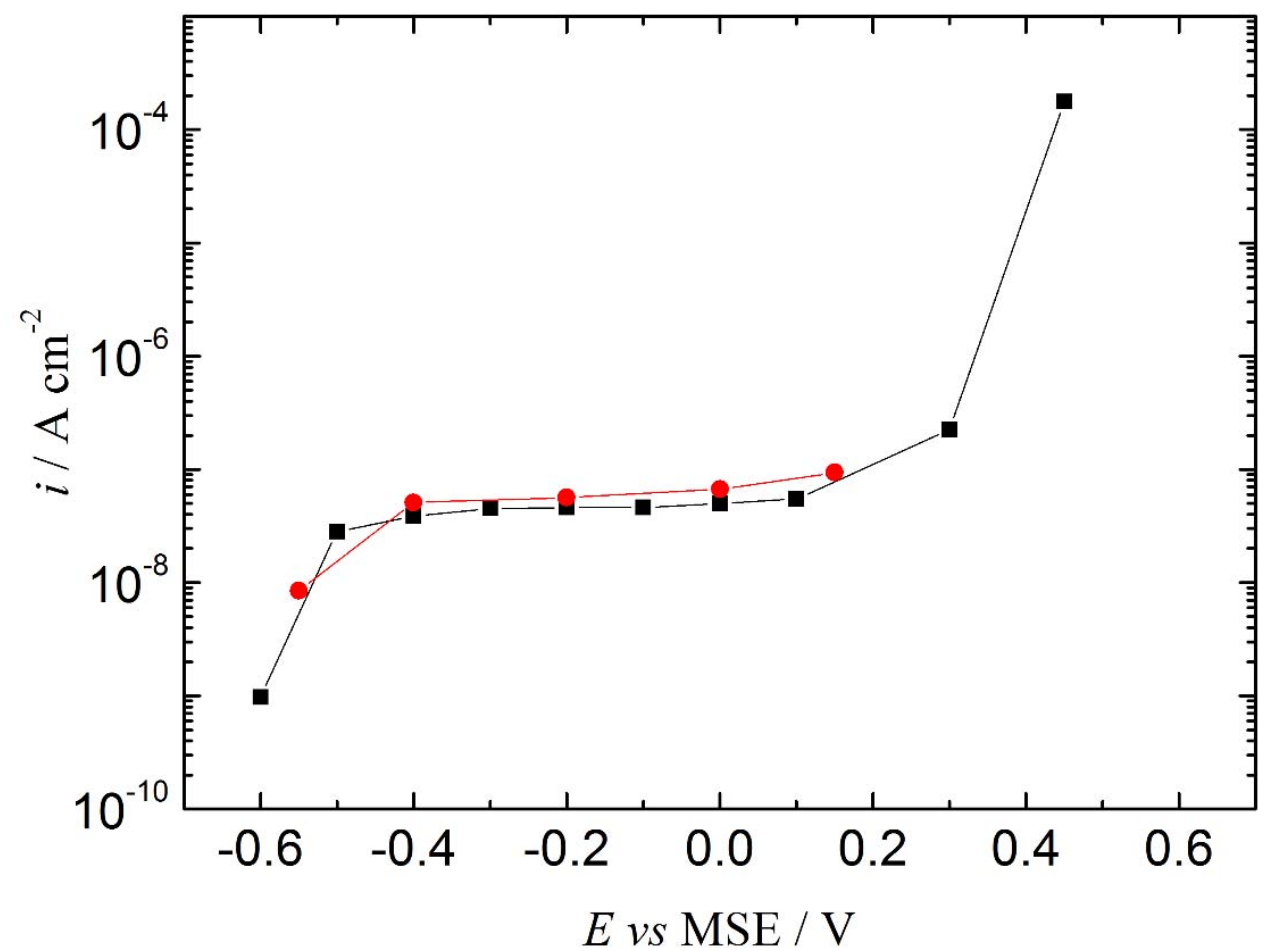

Figure 2

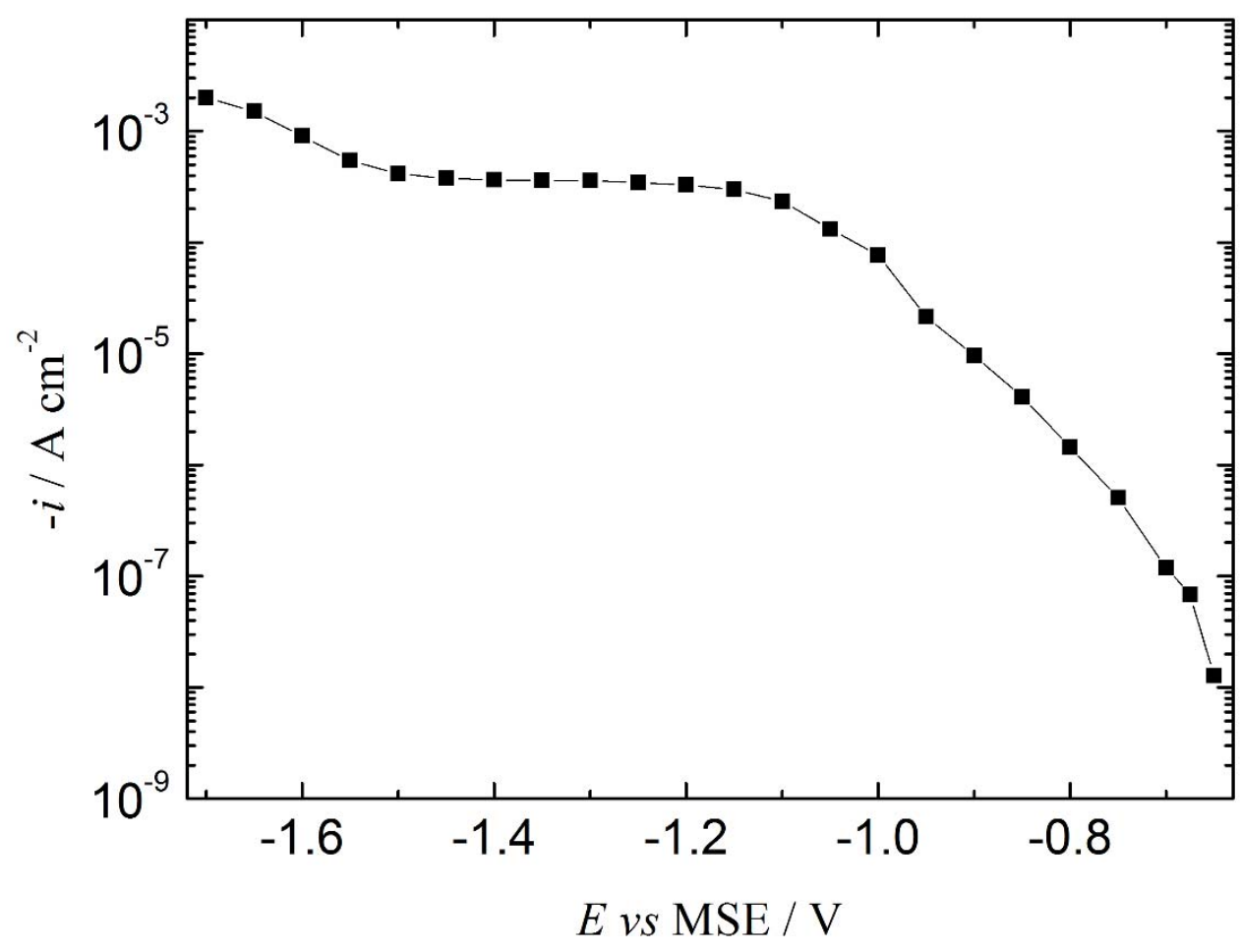


Figure 3

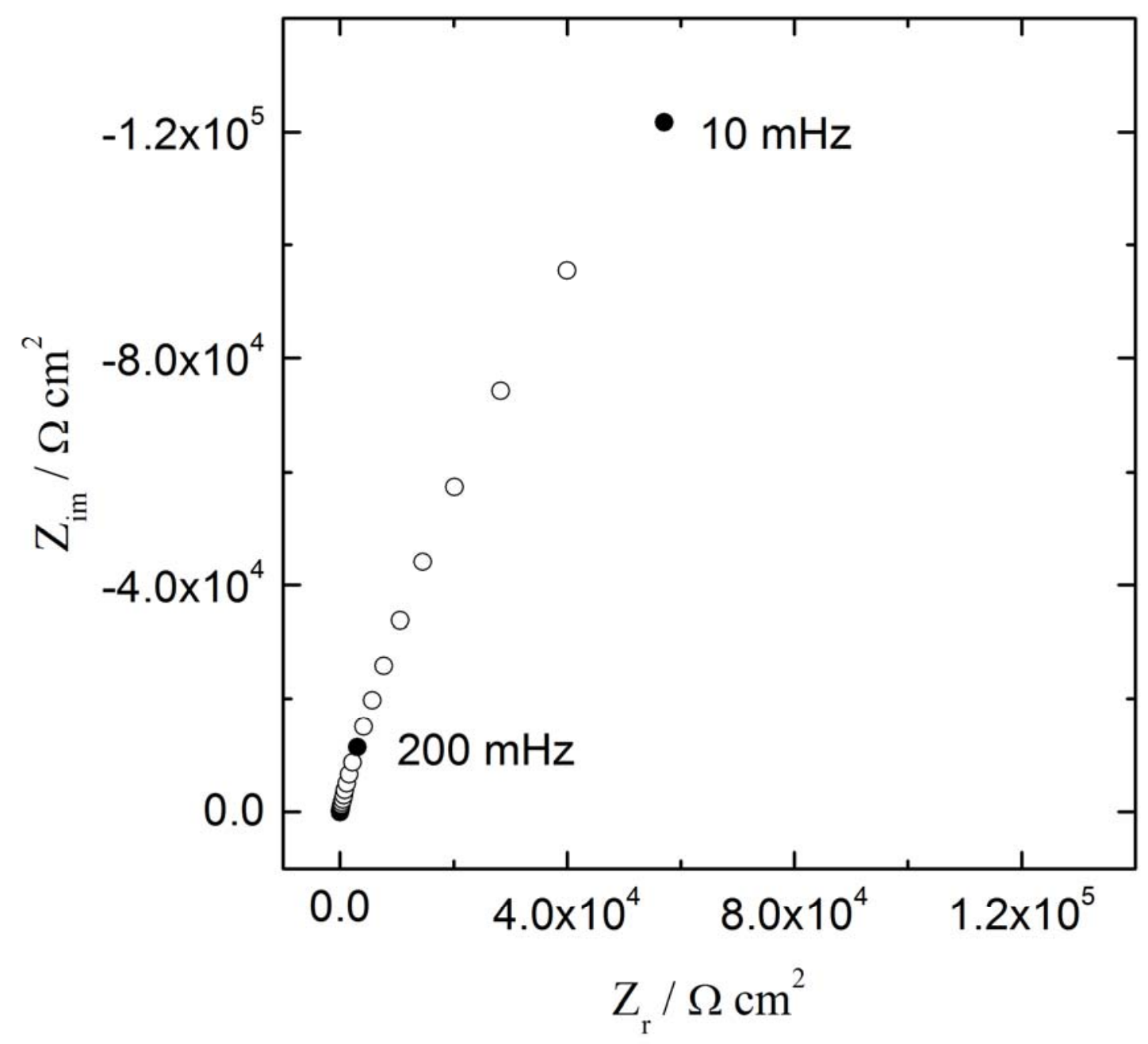


Figure 4

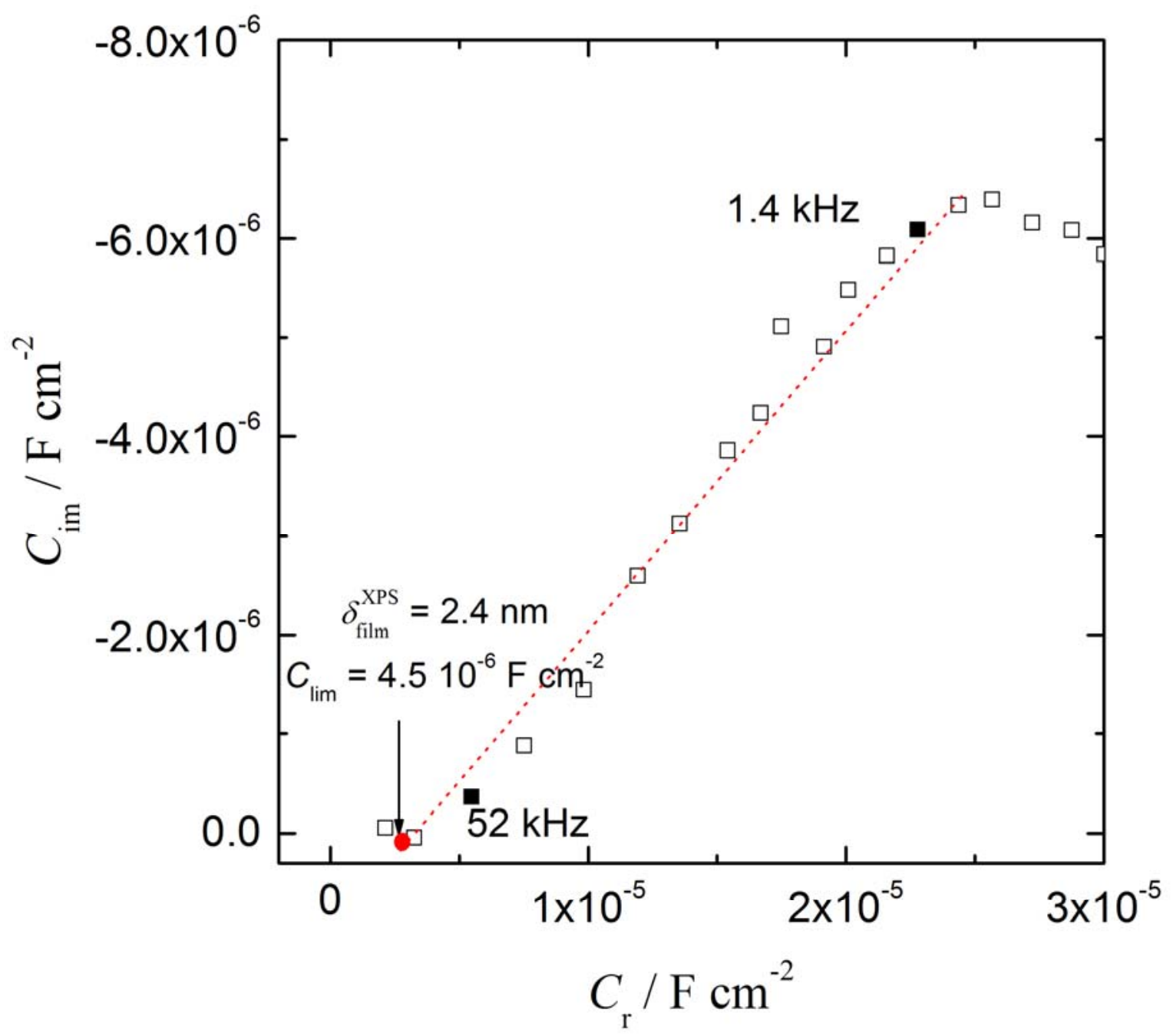


Figure 5
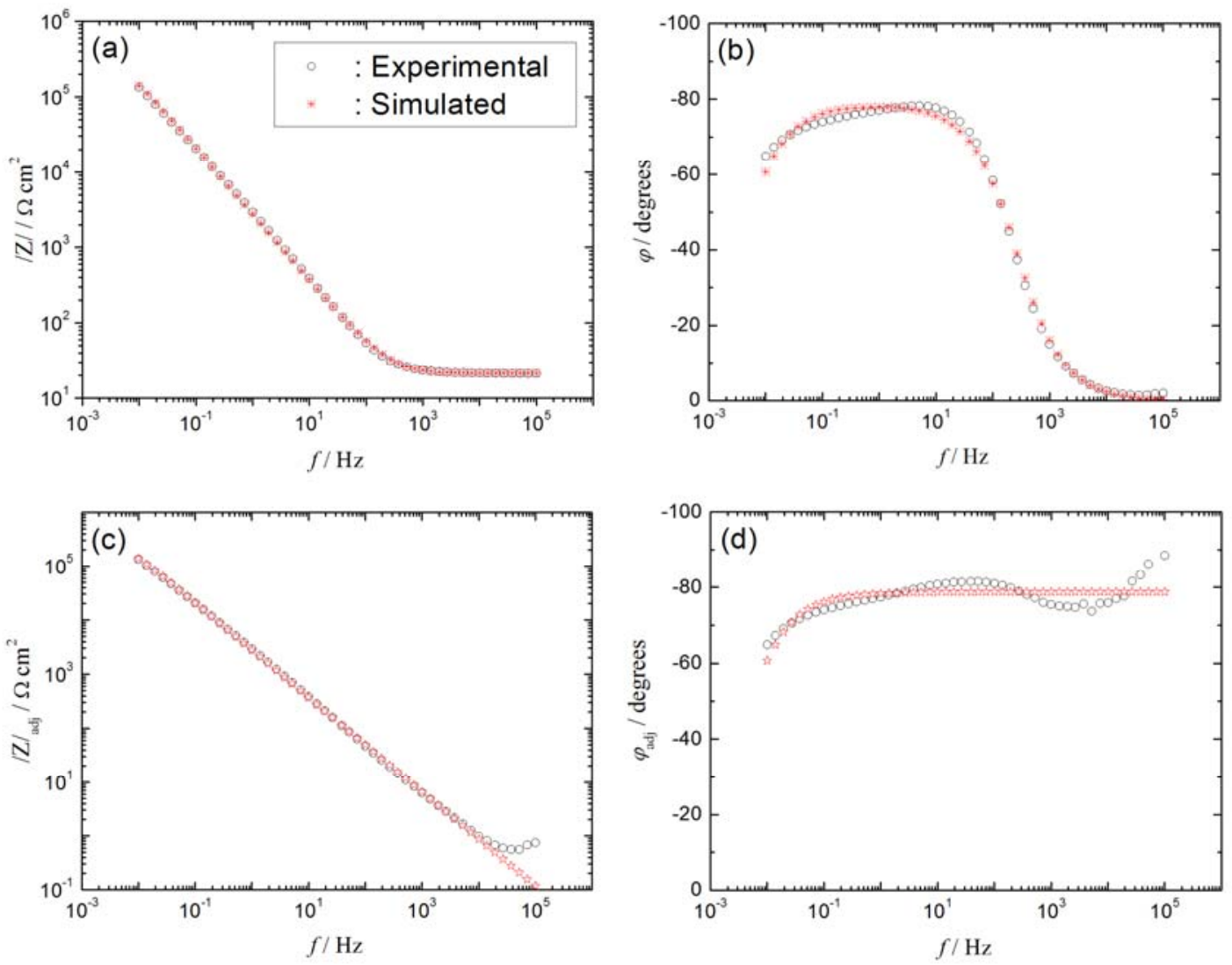
Figure 6

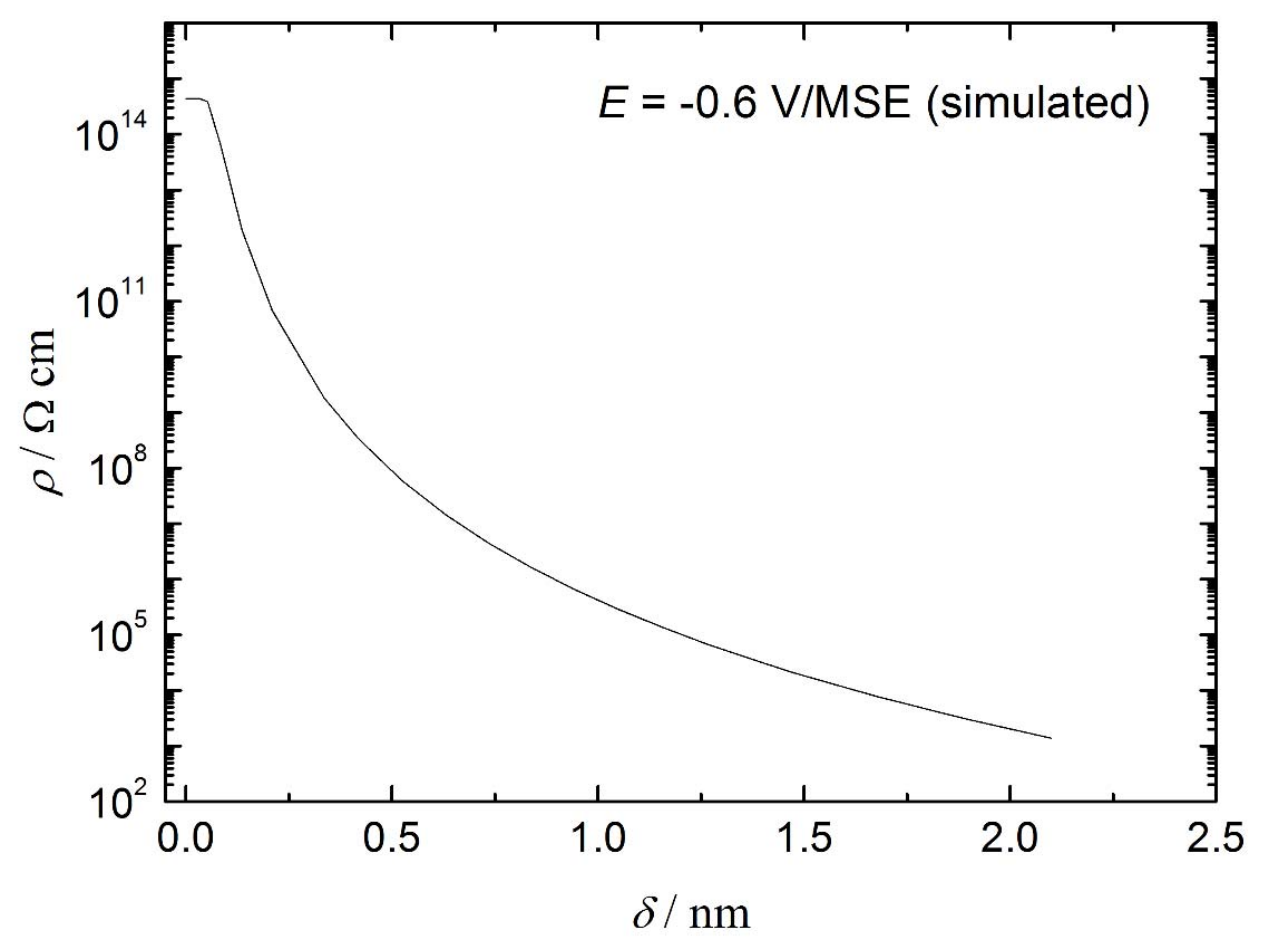

Figure 7

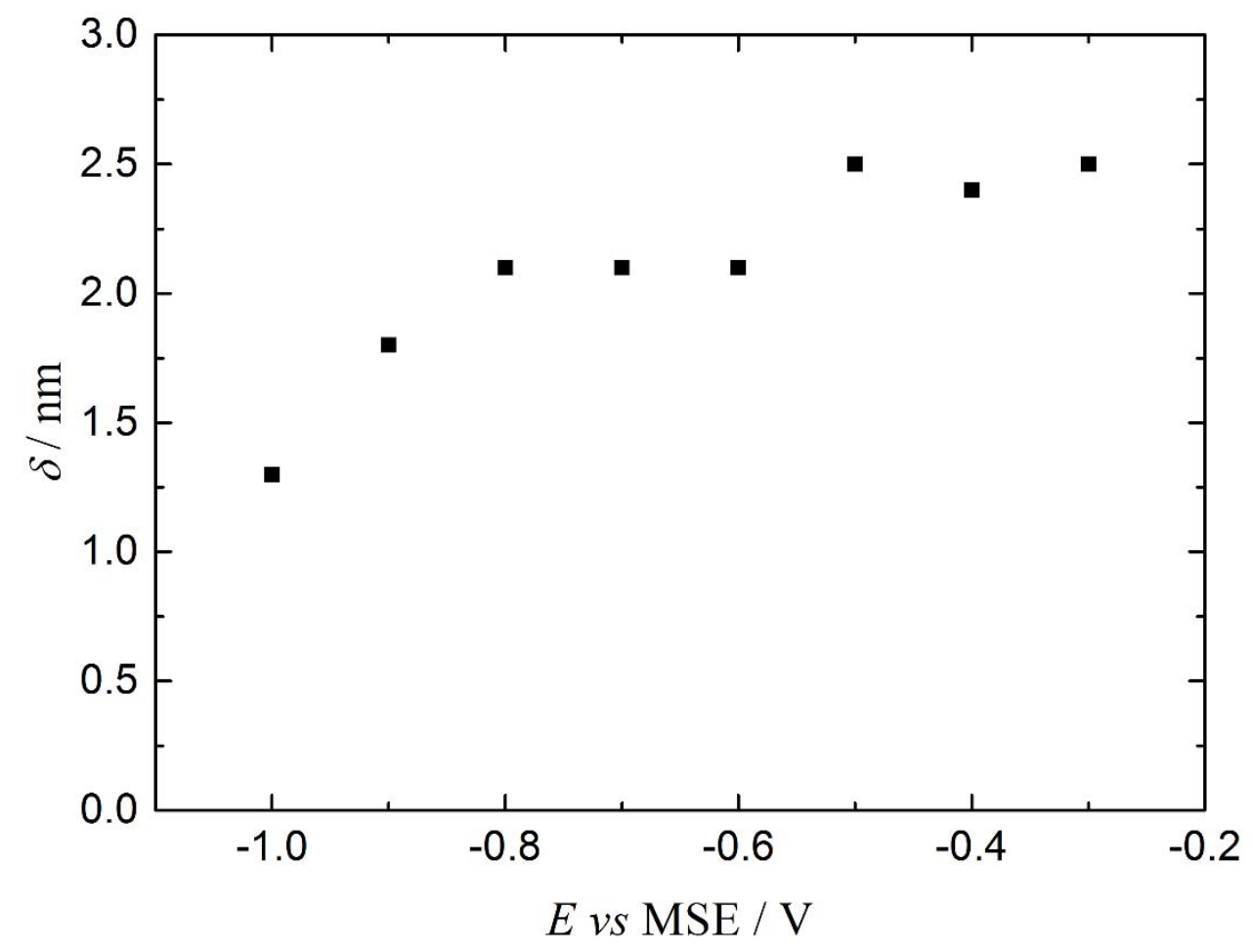


Figure 8

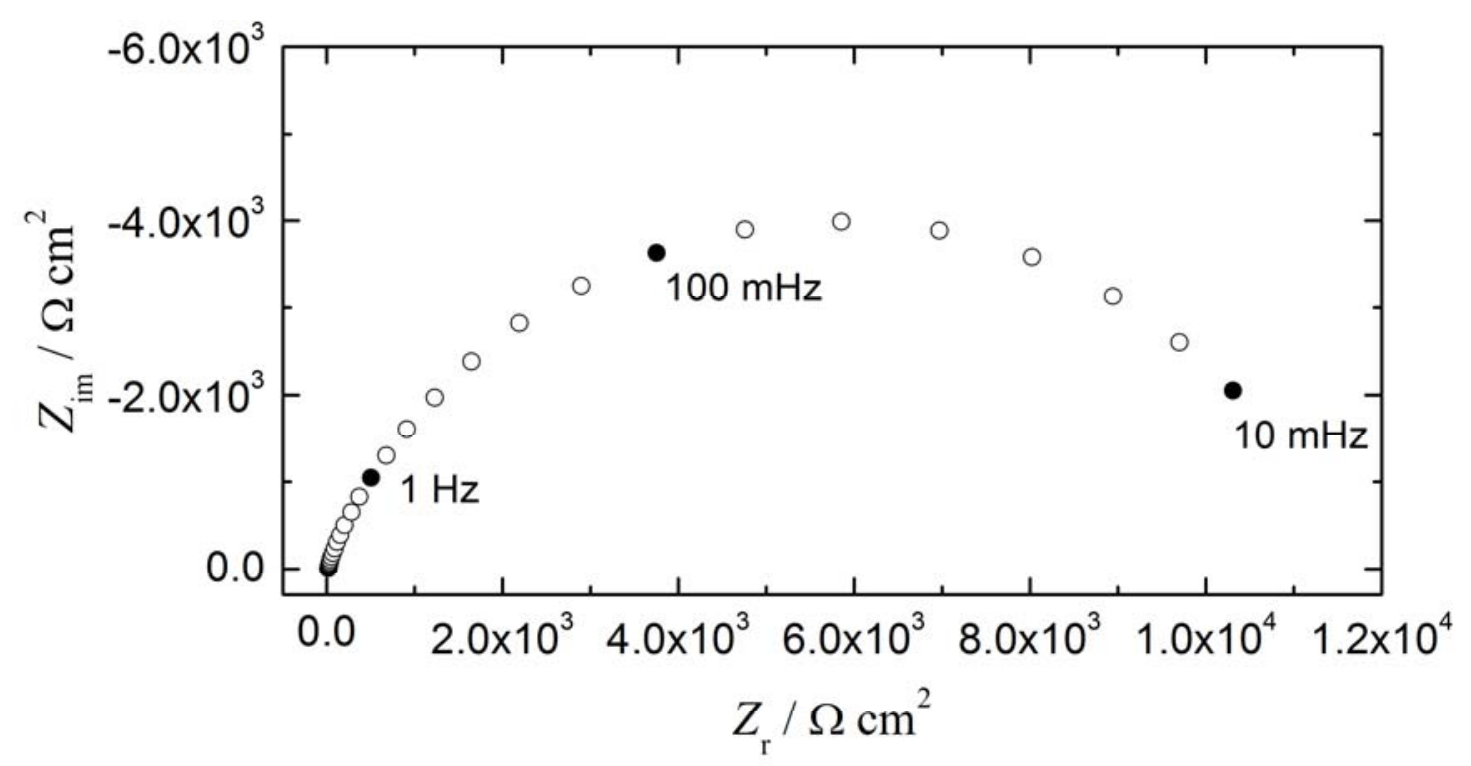

Figure 9

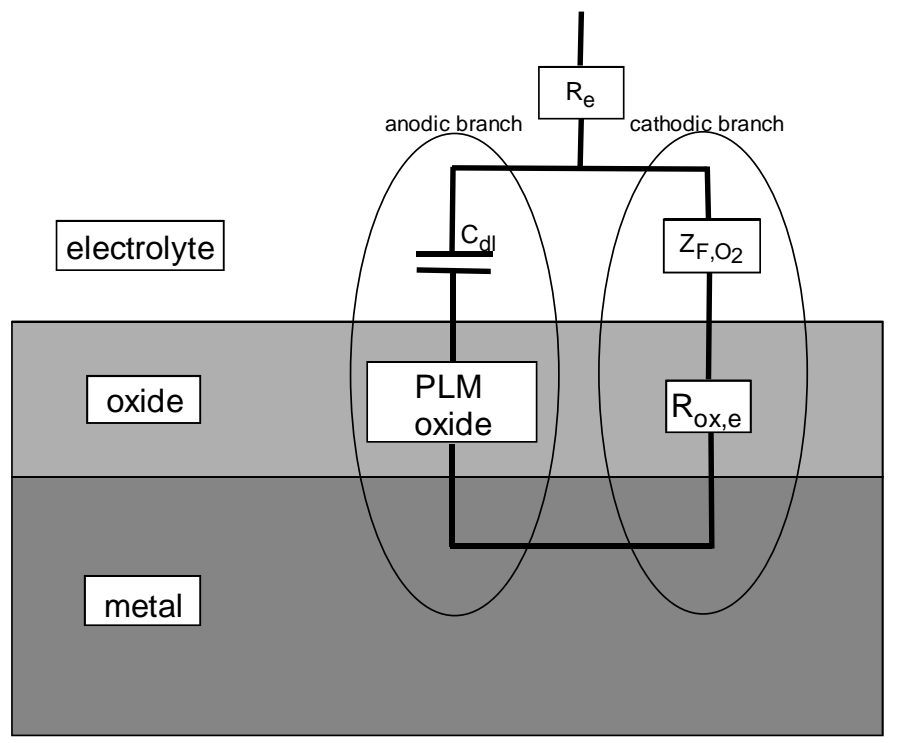


Figure 10

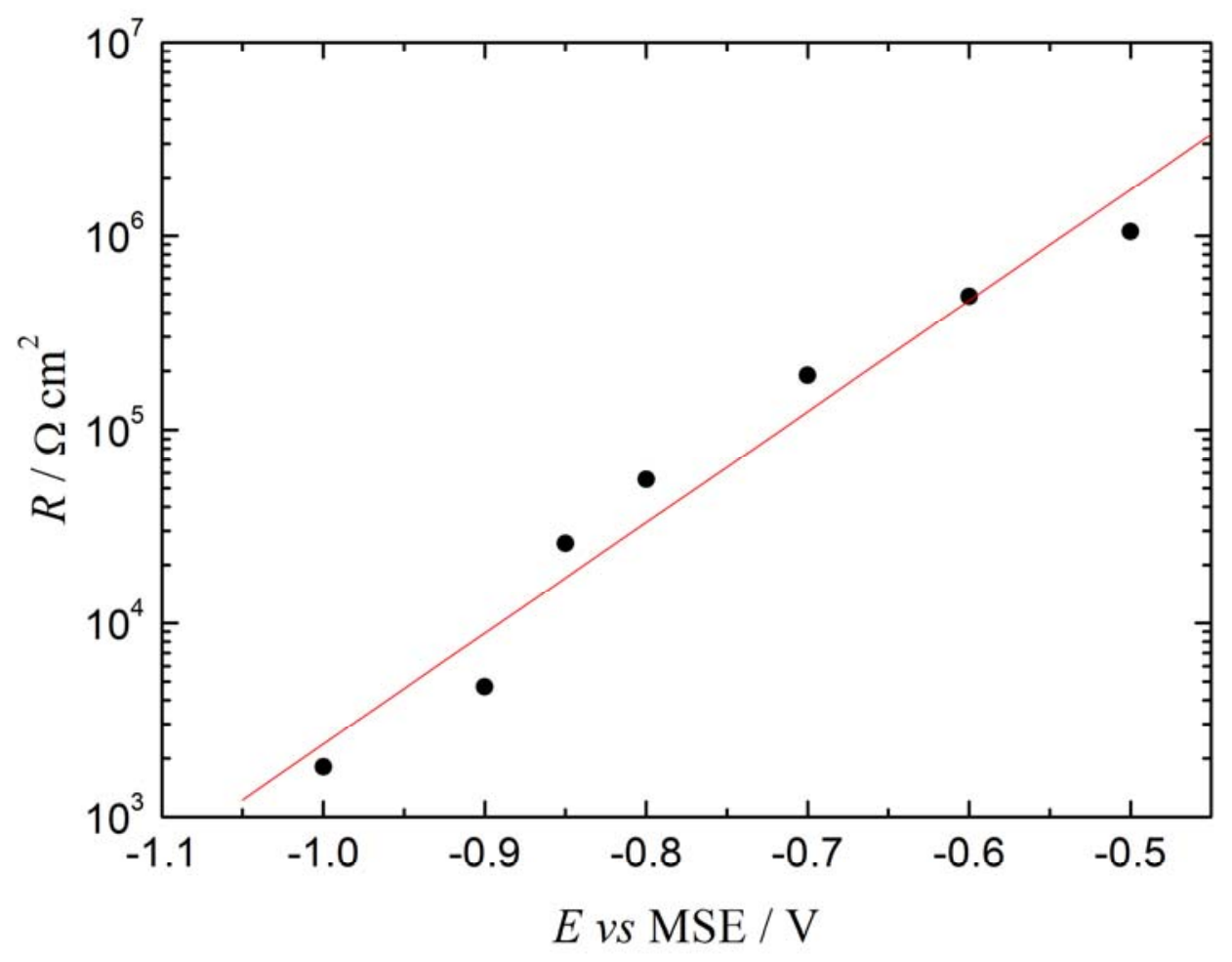

